\title{
SELLADO Y RECUPERACIÓN DE ANTIGUOS VERTEDEROS DE RESIDUOS SÓLIDOS URBANOS
}

\author{
(SEALED AND RECOVERY OF OLD DUMPING PLACES OF SOLID URBAN REMAINDERS)
}

\author{
Isabel Otero; Ana Pilar Espluga; Carmen Ortega \\ Departamento de Proyectos y Planificación Rural \\ Universidad Politécnica de Madrid \\ ESPAÑA
}

Fecha de recepción: $24 \cdot \mathrm{VII}-90$

\section{RESUMEN}

El articulo se centra básicamente en el proyecto de sellado y recuperación de los antiguos vertederos de residuos sólidos urbanos de los Municipios de Ribera Baja, Lantarón, y Valdegovia (Alava), realizado para la Diputación Foral de Alava dentro del Plan Director de Gestión de Residuos Sólidos Urbanos. El acento se pone principalmente en la descripción de una serie de problemas tipo y de las medidas correctoras adoptadas (retirada de vertidos, sellado, remodelación del terreno, siembras y plantaciones). Por último se expone el estudio de localización de una escombrera en el término municipal de Lantarón.
SUMMARY

The paper describes a reclamation project for several solid wastes disposal areas in three small municipalities of the province of Alava, within the 'Plan Director' of Urban Solid Wastes Management. Problems common to these areas as well as reclamation measures (refuse disposal, sealing-off, terrain morphology, landscaping), are emphasized. A study for locating a dumping zone is also included.

\section{INTRODUCCIÓN}

La incidencia de la actividad humana sobre el medio se ha hecho sentir de modo preocupante en numerosas ocasiones; el espacio donde se realizan estas actividades se transforma planteándose así una problemática compleja en torno a la actividad antrópica como foco y origen principal del proceso. De entre los muchos problemas que se derivan de la presencia y actuación del hombre sobre determinadas zonas, cabe destacar, por su relación con el proyecto que nos ocupa, todos aquéllos asociados a los productos materiales, sustancias o desechos que dan lugar a restos o residuos no directamente utilizables por él y que por lo tanto se vierten en el territorio de forma muchas veces incontralada; surge entonces el problema de la contaminación "presencia y persistencia de materias, cualesquiera que sea su composición, en ambientes que de modo natural no les corresponden".
El caso de los residuos sólidos urbanos (residuos sólidos inertes y basuras) se encuadra claramente dentro de la problemática enunciada; hoy dia la adecuada gestión de este tipo de residuos (ubicación de vertederos sanitariamente controlados, recogida de residuos, transporte, sellado, etc.) adquiere una capital importancia especialmente cuando la población aumenta y se producen grandes cantidades de desechos.

El sellado y recuperación de antiguos vertederos de residuos, se plantea así como una de las soluciones a adoptar para lograr una gestión óptima del problema; el sellado y posterior recuperación de antiguos vertederos para otros usos, como puedan ser recreativo, forestal, agrícola, etc., constituye uno de los casos más nitidos dentro de la tipologia de la Recuperación de Tierras orientado básicamente a la supresión de focos puntuales de contaminación, y a la restitución de la ca. lidad ecológica y paisajística. 
Sobre el tema se ha escrito de modo extenso, particularmente en la literatura especializada, a donde se remite al lector para un conocimiento más detallado de los aspectos particulares del problema. La bibliografía que aporta el presente artículo constituye tan sólo una pequeña muestra, que intenta ser precisa, del in. terés científico suscitado en torno al problema de los residuos sólidos urbanos, su tratamiento y recuperación y la restauración de los terrenos afectados por dicha actividad.

Se pasa así, a continuación, a la descripción y análisis de un proyecto concreto de restauración: el proyecto de sellado y recuperación de los antiguos vertederos de residuos sólidos urbanos de los Municipios de Ribera Baja, Lantarón y Valdegovía (Álava), realizado por encargo de la Diputación Foral de Álava.

Este proyecto responde o se inserta dentro del Plan Director de Gestión de Residuos Sólidos Urbanos, y más concretamente a los Planes Zonales de Restauración de Vertederos Incontrolados y Escombreras, elaborados por la Dirección General de Medio Ambiente de la Diputación Foral de Álava.

\section{OBJETIVOS Y METODOLOGIA}

La comarca Alavesa se puede caracterizar, desde el punto de vista paisajístico, por la presencia de una notable variedad de paisajes diferentes consecuencia fundamentalmente de sus atributos morfológicos y de uso del suelo.

En los últimos años, las características de este paisaje se han visto perturbadas por un acelerado desarro- llo urbano, que aunque sujeto a un Planeamiento Ur. banistico técnicamente correcto, se distorsiona puntualmente, dando lugar, entre otros problemas, a la proliferación de grandes escombreras y vertederos incontrolados; a esta circunstancia habría que sumar, además, el efecto contaminante de las basuras vertidas directamente, en numerosas ocasiones, en las orillas de ríos y arroyos.

El diseño de una solución global al problema planteado pasaría en primera instancia por un proceso de ordenación territorial, que se concretaría más adelante en acciones definidas como la clausura de vertederos incontrolados, la gestión de posibles áreas que reunan las adecuadas condiciones de orden topográfico, geográfico, hidrológico, etc., para concentrar los Residuos Sólidos Urbanos, que se originen en un cierto territorio y establecer de este modo una red de vertederos sanitariamente controlados. Si nos referimos ahora a objetivos concretos, el problema se circunscribe, por una parte, a evitar la continuidad de los vertidos en determinados puntos, y por otra a rehabilitar el uso de un territorio hasta ahora dedicado a otros fines. En ambos casos el objetivo común se centra en la integración del vertedero en el paisaje circundante. Para la consecución de este fin es necesario acudir al proceso de Sellado de Vertederos consistente en cubrir la basura con tierra, una vez compactada. Puede darse la conveniencia de retirar aquélla en el caso de que la zona donde esté ubicado el vertedero presente riesgo de contaminación.

Por lo que se refiere a la metodología seguida para la elaboración del proyecto se puede esquematizar tal y como aparece en el fluxograma siguiente:

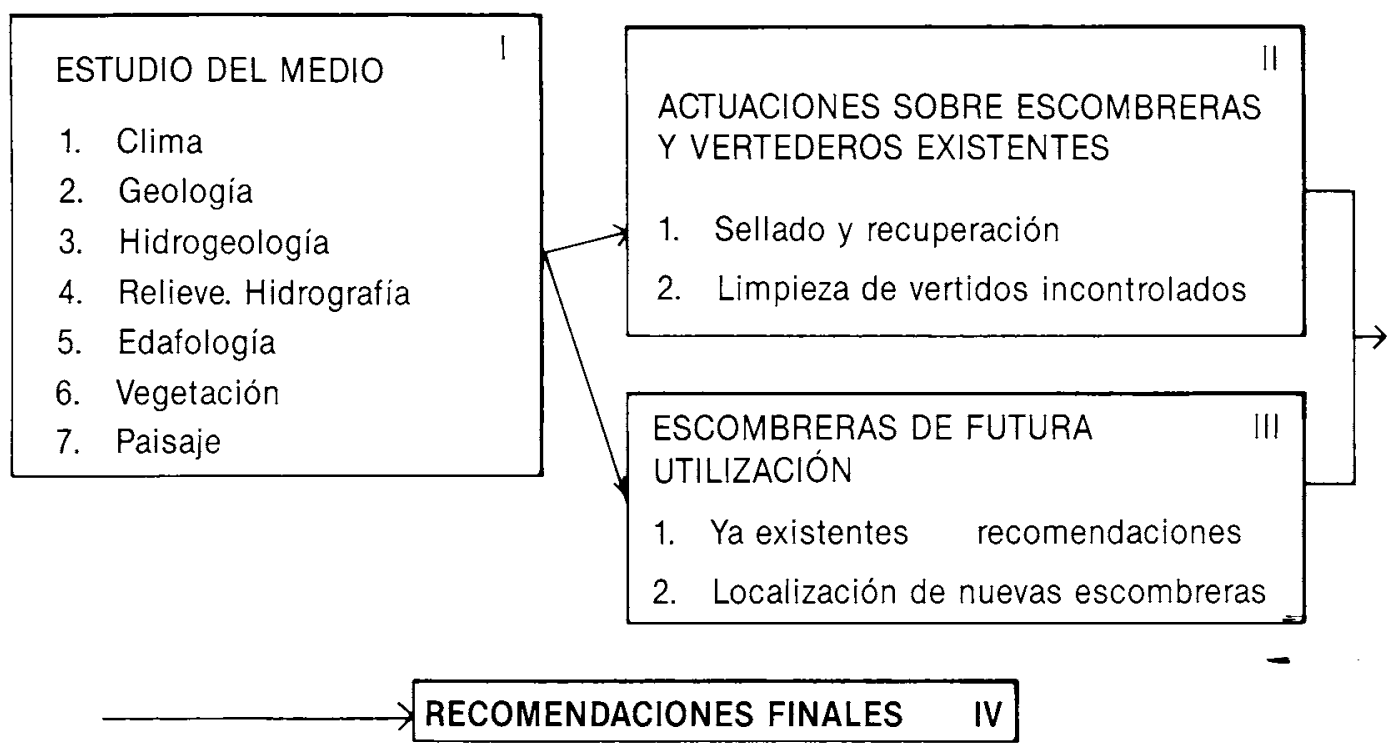




\section{ESTUDIO DEL MEDIO}

Desde un punto de vista global, los elementos del medio que resulta necesario describir y perfilan, además, el ámbito del proyecto son: clima, geologia, hidrogeologia, relieve-hidrografía, edafologia, vegetación y paisaje.

La importancia e interés del estudio de estos parámetros, en el ámbito del proyecto, se puede significar conforme a su relación con problemas de riesgo, adecuación ecológica al medio o diseño, según aparece reflejado en el Cuadro I.

A continuación se describen los elementos seleccionados; de una manera general se presentan sus principales aspectos y particularidades.

\section{CLIMA}

El clima general del área objeto del proyecto es mediterráneo continental, con precipitaciones menores que en zonas más septentrionales y con un marcado estio. Todo ello debido al efecto pantalla de las sierras de Cantabria. Sin embargo, para definir más exactamente las características climáticas de esta zona es necesario diferenciar dos grandes subzonas. La primera de ellas incluye los puntos situados en el término de Valdegovía. La segunda, más meridional, corresponde a los términos de Lantarón y Ribera Baja. Las estaciones escogidas como representativas de cada zona son Bóveda y Miranda de Ebro respectivamente.

Los problemas fundamentales en la definición del clima de la zona son la orografía y las variaciones de régimen pluviométrico incluso para pequeñas distancias.

\section{GEOLOGIA}

La geologia de la zona que contempla el proyecto está representada localmente por materiales del Secundario (Bóveda, Fresneda, Osma) y Terciario (Salcedo), y más extensamente por el Cuaternario (ambos lados del rio Zadorra).
El Cretácico Superior, último periodo del Secundario, está representado por sedimentos calcáreos margosos y terrigenos, de edades comprendidas entre el Santoniense superior y Maastrichtiense. Se pueden encontrar bien estratificadas, calizas y calcarenitas entre las que se intercalan delgadas juntas margosas. Esta distinta resistencia de los materiales provoca una marcada erosión diferencial que da lugar a un relieve abrupto, acentuado por las estructuras de plegamiento NWSE del anticlinal de La Hoz.

El terciario está representado en la zona del proyecto por dos series diferentes: la correspondiente al vertedero de Salcedo y la escombrera de doble piso en el Término Municipal de Lantarón por un lado, y la de ViIlanueva de Valdegovía por otro, límite ésta, entre el Terciario y Cuaternario.

La primera de ellas pertenece al Mioceno inferior y medio. Constituye la serie un conjunto de areniscas en paleocanales y arcillas de tonos pardo amarillentos.

Villanueva de Valdegovía se presenta en el límite entre dos formaciones geológicas distintas, una dentro del terciario y otra incluida en el cuaternario. Los materiales representativos del terciario son arcillas rojas con intercalaciones de conglomerados, cuyas edades van del Mioceno inferior al superior. El cuaternario abarca en esta zona sólo el Holoceno. Se pueden distinguir los aluviones y la primera terraza de bolos y cantos de cuarzo y cuarcitas y matriz arenoso-arcillosa excavada por los aluviones actuales. Los depósitos de fondo de valle se caracterizan por la abundancia de fracción arcillosa que engloba los cantos. Las zonas de Espejo, Bergüenda y las escombreras situadas en la carretera de Fontecha a Miranda se encuadran también dentro del Holoceno por lo que responden a la descripción anterior.

Ribabellosa pertenece a la terraza media baja del río Ebro. Sus materiales son cantos y bolos de cuarzo y cuarcita subredondeados, englobados en una matriz arenosa y limolítica de tonos pardos y rojizos del Pleistoceno.

\section{Cuadro I}

\begin{tabular}{|l|c|c|c|}
\hline PARÁMETRO & $\begin{array}{c}\text { PROBLEMAS } \\
\text { DE RIESGOS }\end{array}$ & $\begin{array}{c}\text { ADECUACIÓN } \\
\text { ECOLÓGICA }\end{array}$ & ASPECTOS DE DISEÑO \\
\hline - Clima & Castástrofes & Adaptación & Épocas de ejecución \\
- Geologia & Contaminación & Adaptación & - \\
- Vegetación & - & Adaptación & Integ. paisajística \\
- Edafologia & Contaminación & - & - \\
- Hidrogeologia & Contaminación & - & Integ. paisajistica \\
- Relieve y paisaje & Contaminación & - & Integ. paisajistica \\
\hline
\end{tabular}




\section{HIDROGEOLOGIA}

Los puntos más septentrionales, de la zona del proyecto, entorno de Bóveda, presentan poco interés hidro geológico. Dado el tipo de materiales, caliza arcillosa o arcilla arenosa, la formación de acuiferos colgados es de escasa importancia.

Los puntos más meridionales, término de Lantarón y Ribera Baja, considerados de forma general, constituyen una alternancia de niveles permeables e impermeables que provocan la existencia de pequeños acuíferos que descargan en la mayoria de los casos por medio de fuentes.

\section{RELIEVE. HIDROGRAFIA}

En la zona del proyecto, el relieve muestra marcadas diferencias entre la parte más noroccidental y la situada más al sur.

En el extremo W aparecen las Sierras de Arcamo, Arana y Peña Gorria con orientación NW-SE. Son grandes elevaciones con acantilados que delimitan amplias extensiones de llanuras altas. En las partes bajas, se encuentran valles anchos y suaves en los que se incluyen ocasionalmente montículos de elevación media. El punto más elevado de la zona corresponde al pico de El Lerón (1.240 m), cercano a Bóveda.

El río Omecillo atraviesa Bóveda, así como Villanueva de Valdegovía donde a su vez se juntan el río Nograro, Arroyo de S. Martín y Barranco del Corral.

El valle del rio Omecillo avanza hacia el sur por un relieve suave de pequeñas ondulaciones cuya altura me. dia oscila entre 400-600 m. No existe ninguna cota destacable en esta zona de las terrazas del Ebro, sin em. bargo es notable la red de arroyos y barrancos que desembocan al río Ebro. Cabe destacar, además del Ome. cillo que pasa por Espejo y Bergüenda, el arroyo de los Moros cercano a Salcedo y el río Bayas en las proximidades de Ribabellosa.

\section{EDAFOLOGÍA}

El territorio perteneciente a los tres términos municipales dentro de la llanada de Vitoria y Sierras calcáreas occidentales, presenta como tipo de suelo dominante los cambisoles cálcicos en ocasiones con inclusiones de regosol calcárico.
La principal característica de los cambisoles es la presencia de un horizonte $B$ de alteración, expresada por génesis de arcilla, liberación de óxidos de hierro que tiñen de pardo o rojo, redistribución de carbonato cálcico, o hidromorfía.

Aparecen fundamentalmente en áreas con pendiente suave o moderada. Sin embargo, cuando ésta aumenta, se asocian a los regosoles para cualquier condición climática, tanto de temperatura como de pluviosidad.

Los cambisoles cálcicos poseen carbonato cálcico en el horizonte $B$, y casi siempre también en el A. La roca madre sobre la que se desarrollan es siempre caliza con contenidos altos de arcilla o limo.

Cuando no existen limitaciones por pendiente, pedregosidad o roca cercana a la superficie, se utilizan normalmente para el cultivo de cereal.

\section{VEGETACIÓN}

La gran diversidad de factores tanto climáticos como topográficos que se dan dentro del marco territorial de la provincia, deriva, a su vez, en una gran diversidad de formaciones vegetales. La mayoria de las cadenas montañosas presentan una orientación Este-Oeste, que provoca una clara diferenciación entre la vegetación de las vertientes norte y sur. El aire cargado de humedad procedente del Cantábrico, descarga sobre las umbrias, permitiendo la ubicación de formaciones como la del hayedo. Este aire, por el contrario, llega seco y recalentado a las solanas (efecto Fohën), apareciendo como formaciones representativas de estas condiciones, el encinar y carrascal. Tipos intermedios de estas dos condiciones bien diferenciadas son, por ejemplo, los marojales, los quejigales o las formaciones mixtas de estas frondosas con el pino silvestre.

A esta diversidad ecológica hay que añadir la acción del hombre (talas, incendios, pastoreo, laboreo) modificando estas comunidades o formaciones originales, dando lugar a otras nuevas por degradación.

Se detallan a continuación, de modo esquemático, las formaciones vegetales presentes dentro del marco territorial objeto del Proyecto, diferenciando para ello dos grandes áreas: la primera de ellas, llamada "Comarca de los Valles" (A), corresponde al término municipal de Valdegovia, y la segunda incluye los términos de Lan. tarón y Ribera Baja (B), claramente diferenciada de la anterior. 
1) Carrascal montano: Quercus ilex, Juniperus $s p$., Quercus faginea, Acer monspessulanum, Phillyrea latifolia, Erica vagans, Spireae hispánica, Cistus salvifolius-A, B.

2) Hayedo subcantábrico: Fagus sylvática, Ilex aquifolium, Taxus baccata, Acer campestre, Sorbus aria, Crataegus monogyna y Crataegus laevigata-A.

3) Pinares montanos con boj: Pinus Sylvestris, Buxus sempervirens, Quercus sp., Juniperus sp., Arctostaphylos uva-ursi-A.

4) Quejigales: Quercus faginea, Acer monspessulanum y Juniperus communis sobre estrato subarbustivo y herbaceo-A, B.

5) Formaciones arbustivas

- Coscojares (Quercus coccifera)-A.

- Matorral de enebro y sabina (Juníperus oxycedrus, Juniperus sabina, Thymus vulgaris, Lavándula latifolia, Genista scorpius)-A.

- Matorral de brezo y árgoma (Erica arborea, Erica cinerea, Calluna vulgaris, Ulex sp.)-A.

6) Formaciones herbáceas

- Pre-landa (Brachypodium pinnatum, Erica vagans)-A.

- Pastos mesófilos (Bromus erectus, Festuca rubra)-A, B.

7) Vegetación de ribera: Alnus glutinosa, Salix atrocinerea, Fraxinus excelsior, Ulmus minor, Acer campestre, Corylus avellana-A, B.

8) Cultivos (cereales, remolacha y patata)-B.

9) Matorral de enebro y sabina negra-B.

10) Pastizal xerófilo: Festuca indigesta, Koeleria vallesiana, Carex humilis-B.

\section{PAISAJE}

La totalidad del área objeto de estudio puede dividirse, atendiendo a los caracteres paisajísticos, en dos grandes subáreas que se consideran homogéneas desde ese punto de vista, y que coinciden, groso modo, con la división adoptada al tratar los demás apartados.
La primera de ellas, corresponde al término territorial de Valdegovía también Ilamado Comarca de los Valles. Se caracteriza por un relieve abrupto derivado del tipo de roca subyacente, calizas duras, de consistencia muy resistente, que dan lugar en numerosas ocasiones a auténticos paredones y torcales. Dominan el paisaje dos alineaciones de orientación Noroeste-Sureste: la Sierra de Arcano y paraiela a ella, pero situada más al sur la de Arcena. Estas dos alineaciones delimitan el valle del rio Omecillo, que marca la característica más sobresaliente del paisaje y en el que se diferencian con claridad dos tipos de orientaciones principales, las solanas y las umbrías.

Al rio Omecillo, vierten toda una serie de pequeños ríos y arroyos que configuran, sobre el terreno, una red de barrancos y pequeños valles transversos al principal que se reflejan en el paisaje por una superposición con. tinua de planos. En las solanas dominan los pinares, casi siempre entremezclados con otras especies frondosas (Quejigos, Arces, Carrasca), dando paso en las cotas inferiores a cultivos, pastos y matorrales con una estructura derivada de la actuación del hombre (tala, incendio), dominando en estas últimas las especies autóctonas principales (Quejigo, Carrasca) junto a enebros, sabinas, boj, etc.

En las laderas frescas de las umbrias, continuan los pinares, en mezcla con el haya, o dominando ésta en las cotas más elevadas, como en Peña Gorria. Por en. cima del hayedo se instala un matorral bajo en mezcla de brezo y otras especies.

Los fondos de valles están ocupados por cultivos, separados aún por setos, constituidos por un estrato arbóreo, en algunos casos, y un estrato arbustivo. En las riberas del Omecillo y de sus principales afluentes Tumecillo y Arroyo Pinedo, las alisedas se asientan en perfecta alineación.

En los valles altos, entre Peña Gorria y Lerón y Sierra Arcena, domina el brezal entremezclado con los prados de guadaña y con rodales de hayedo, surgen también de nuevo los pinares en mezcla con hayas y quejigos en el extremo más oriental, que dejan paso, en las solanas, a los carrascales con boj.

La segunda gran subárea corresponde a los términos de Lantarón y Ribera Baja. Su paisaje se caracteriza por extensos espacios abiertos, que son lasterrazas bajas del Omecillo y del Ebro, ocupadas en su totalidad por cultivos. Las terrazas superiores, cada vez de me- 
nor extensión, marcan un paisaje ondulado con cotas crecientes, hasta los $800 \mathrm{~m}$ de altitud y recortadas por pequeños valles cerrados, que en general vierten al Ebro, o por una sucesión de cerros aislados, como en las cercanias de Ribabellosa, en el término de Ribera Baja.

Los cultivos son la caracteristica dominante del paisaje y sólo donde la pendiente es más elevada e inhábil al laboreo quedan restos de quejigales y carrascales, en mezcla, a veces, con el pinar, o pastizales, como ocurre en las cabezas de los cerros.

\section{LOCALIZACIÓN DE VERTEDEROS Y ESCOMBRERAS}

Para la localización de los vertederos y escombreras de los tres términos municipales objeto del proyecto, se ha procedido a una prospección del terreno. Esta labor ha consistido, por una parte, en una consulta a los distintos Alcaldes que siempre han facilitado los datos sobre sus ubicaciones y los problemas que de ellos se derivaban y por otro lado en un reconocimiento, in situ, de los núcleos urbanos, vías de acceso y recorrido de los alrededores.

Una vez recogidos los datos, se ha realizado una primera clasificación de núcleos teniendo en cuenta la envergadura de las medidas correctoras. El primer bloque recoge aquellos núcleos con vertederos y escombreras en los que la actuación ha de ser tratada para cada uno en particular debido a las caracteristicas y problemáticas de los vertidos. Y en un segundo bloque aquéllos otros que no poseen puntos de vertido localizados (más bien de forma difusa), debido en muchos casos a sus bajas poblaciones, casi deshabitados y que las medidas correctoras se van a referir, sobre todo, a labores de limpieza.

\section{SELLADO Y RECUPERACIÓN}

De la decisión sobre qué medidas de actuación debian ser las aconsejables o recomendadas, se ha dado prioridad a tres criterios considerados fundamentales. El primero de ellos se fija en la naturaleza de los vertidos, ya sean vertidos sólidos urbanos (basuras) o vertidos sólidos (escombros), con distintos efectos contaminantes y de impacto visual. El segundo criterio se debe a los problemas de contaminación que los vertidos pueden producir (lixiviados, gases). Se han considerado factores limitantes el tipo de sustrato y la proximidad a algún curso de agua. Dentro del tipo de sustrato se descarta cualquier ubicación de vertidos sólidos urbanos (basuras) sobre terrenos cuaternarios, del mismo modo que cualquier emplazamiento de esta misma naturaleza de vertidos sobre márgenes y riberas de cursos de agua. El tercer criterio se fundamenta en la magnitud del impacto visual producido, descartando cualquier punto del terreno de alta visibilidad, cotas de altitud elevadas o proximidad a vias de comunicación.

Las medidas correctoras recomendadas, de acuerdo con estos tres criterios han sido:

- Retirada de vertidos. Para los puntos de vertidos sólidos urbanos (basuras) asentados sobre terrenos cuaternarios en márgenes de ríos o arroyos.

- Sellado. Para los emplazamientos de vertidos sólidos urbanos (basuras) sobre terrenos cuaternarios. Se ha empleado un tipo de suelo cohesivo (arcilla), para evitar problemas de lixiviados y escape de ga. ses contaminantes.

- Remodelación del terreno e integración en el medio. Para todos los enclaves de vertidos pues producen impacto visual elevado. Su tratamiento ha consistido en la remodelación y labores de siembras y plantaciones.

- Una vez recuperado el vertedero se colocará, en un lugar aceptable desde el punto de vista paisajístico, un cartel de la Excma. Diputación Foral según lo señalado en el Pliego de Condiciones.

A continuación se exponen en forma de fichas, las características de los emplazamientos de vertidos que se han considerado más representantivos dentro del conjunto del proyecto, ya sea por las características y problemática de los vertidos o por las soluciones propuestas. 


\section{N. de orden: 2}

Término Municipal: Valdegovia Núcleo: Espejo

- Definición: Vertedero de residuos sólidos urbanos.

- Localización: Talúd sobre el rio Omecillo muy próximo al núcleo urbano.

- Altitud: $500 \mathrm{~m}$.

- Suelo: Cambisol cálcico.

- Geologia: Cuaternario (Holoceno), aluvial limo-arenoso.

- Vegetación: Especies características de ribera con predominio de Alnus glutinosa, Crataegus monogyna, Salix sp., Corylus avellana, Clematis vitalba, Sambucus nigra, junto a otras introducidas como Populus nigra y Populus canadensis y otras características de los vertederos como Rubus $\mathrm{sp}$.

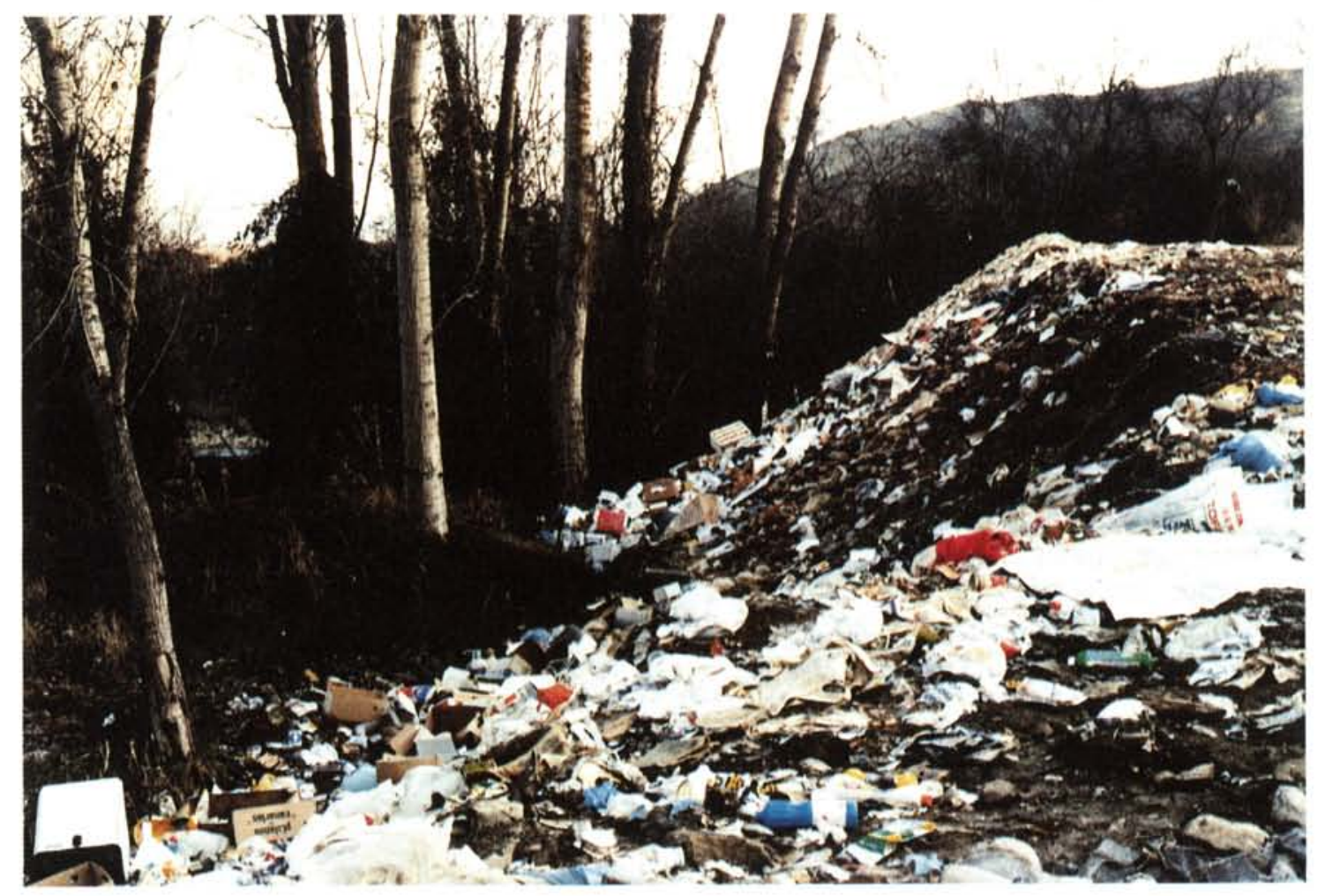

- Caracteristicas y problemática de los vertidos: La problemática de este vertedero debe considerarse desde dos vertientes:

1) Contaminación: por tratarse de vertidos de residuos sólidos urbanos en zonas del Cuaternario y sobre el talúd del río pueden aparecer problemas de contaminación.

2) Impacto visual: constituye un impacto negativo sobre el paisaje de ribera siendo además una zona muy frecuentada por los vecinos de Espejo dada su proximidad al parque urbano.

- Solución propuesta: Como consecuencia de lo expuesto en el apartado anterior se propone levantar el vertedero y los pequeños puntos de vertido en las márgenes, rio abajo, y trasladar las basuras al vertedero controlado de Gardélegui. Antes de proceder a levantarlo se realizará un tratamiento de desratización y desinsectación.

Una vez desalojada la basura se remodelará el terreno dejando los taludes con una pendiente de $45^{\circ}$ y la plataforma del rio con suaves ondulaciones, siguiendo las formas actuales.

Una vez remodelado se aportará una capa de TV., se realizarán unas plantaciones según croquis adjun. to, con ejemplares de Alnus glutinosa, Fraxinus excelsior y Salix atrocinerea y se hidrosembrará con hidrosiembra tipo $\mathrm{H}_{R \cdot(1)}$. 
......

Las especies utilizadas en la siembra serán diferentes según se realice en riberas $(\mathrm{Hr})$ o no (Hs).

Las dosificaciones en cada caso serán las siguientes:

Hr.

Gramineas: Dactylis glomerata

Festuca rubra

Festuca arundinacea

Lolium perenne

Secale cereale.

Hordeum vulgare

Total $85 \mathrm{~kg} / \mathrm{Ha}$

Leguminosas: Lotus corniculatus

Trifolium pratense

Trifolium repens

Medicago sativa

Onobrychis sativa

Vicia sativa

Total $65 \mathrm{~kg} / \mathrm{Ha}$ $\mathrm{kg} / \mathrm{Ha} \mathrm{Hr}$.

Gramineas: Dactylis glomerata

Festuca rubra

Festuca arundinacea

Lolium perenne

Secale cereale.....

Hordeum vulgare

Total $85 \mathrm{~kg} / \mathrm{Ha}$

Leguminosas: Lotus corniculatus

Trifolium pratense

Trifolium repens

Medicago sativa .....

Onobrychis sativa

Total $65 \mathrm{~kg} / \mathrm{Ha}$

10

5

10

15

15 $\mathrm{kg} / \mathrm{Ha}$

15

5

5

10

25

25

Otras: Lavandula latifolia

Thymus vulgaris

Genista scorpius

Sangisorba minor

Total $10 \mathrm{~kg} / \mathrm{Ha}$

10

Total $10 \mathrm{~kg} / \mathrm{Ha}$

Mezcla Total: $160 \mathrm{~kg} / \mathrm{Ha}$

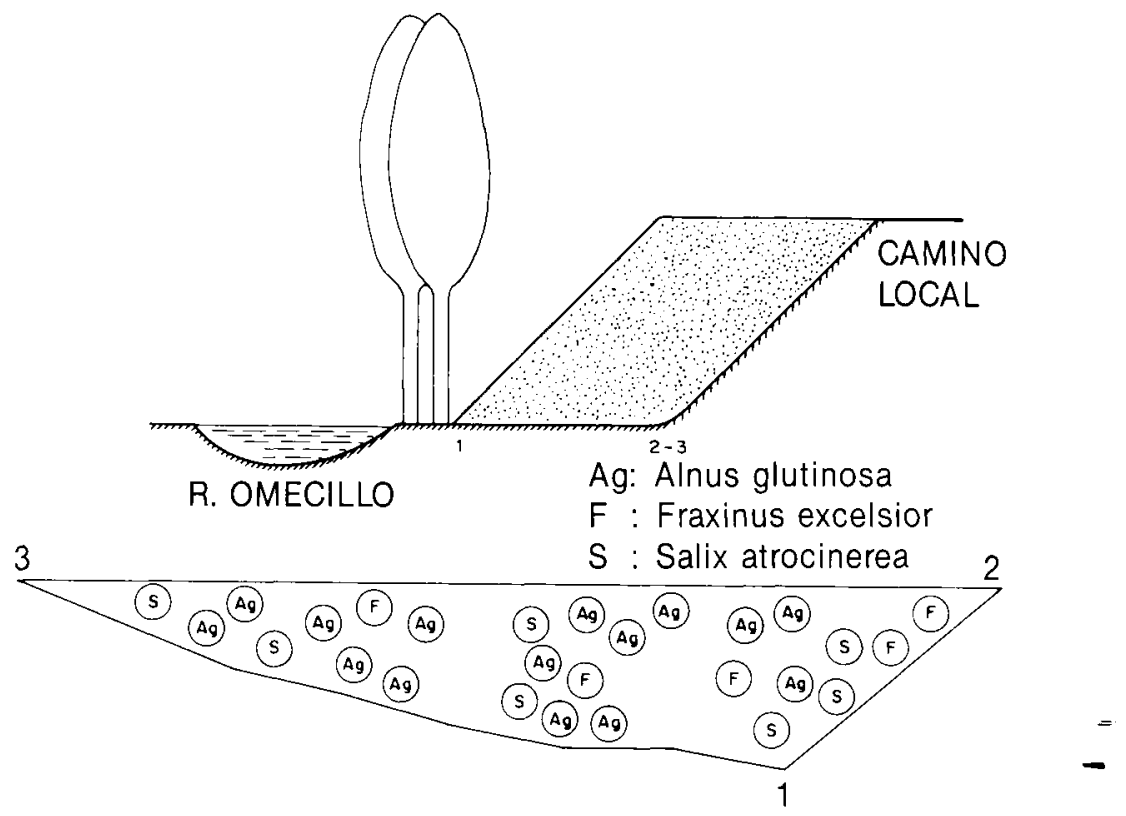

R. OMECILLO

Ag: Alnus glutinosa

$\mathrm{F}$ : Fraxinus excelsior

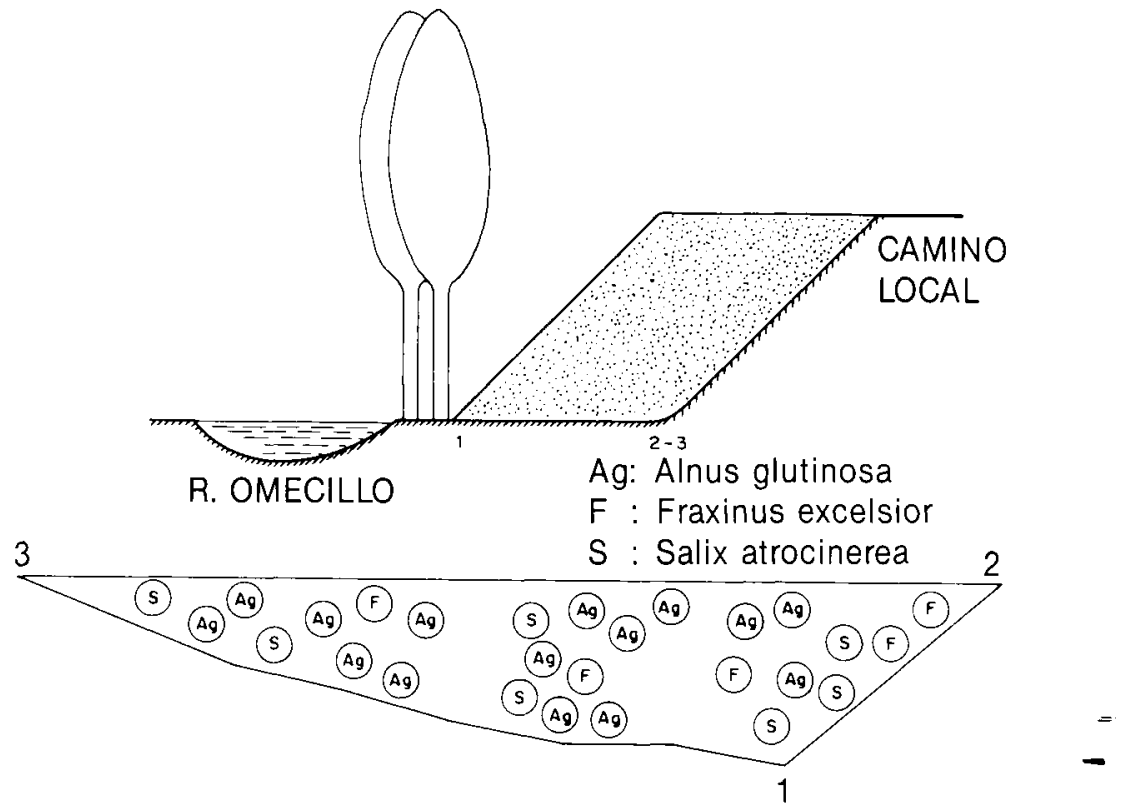

Cornus sanguinea ................................ 2

Sanguisorba minor 


\section{N. de orden: 6}

\section{Término Municipal: Valdegovia}

\section{Núcleo: Osma}

- Definición: Escombrera y vertedero (Escombrera propuesta).

- Localización: Primera desviación a la derecha de la CV-77 desde Osma en dirección a Caranca (a 400 metros de la iglesia aproximadamente).

- Altitud: $600 \mathrm{~m}$.

- Suelo: Cambisol cálcico.

- Geología: Cretácico superior, Coniaciense superior - Santoniense inferior. Sustrato en el que alternan calizas arcillosas y margas.

- Vegetación: La escombrera está localizada entre campos de cultivo en ocasiones abandonados. Aparecen especies como Dactylis glomerata, Festuca ovina y Koeleria vallesiana. Dentro de las gramineas se pueden encontrar también pequeñas agrupaciones de brezo (Erica vagans), algunas zarzas (Rubus sp.) y ejemplares sueltos de pino silvestre (Pinus sylvestris).

- Características y problemática de los vertidos: La ubicación de esta escombrera es idónea ya que pasa totalmente inadvertida en el entorno paisajístico. Su comunicación y acceso es muy bueno puesto que se encuentra al lado de la carretera CV-77 y se ha abierto recientemente un desvio hacia ella. Posee unas dimensiones bastante amplias que permitirán una utilización prolongada.

- Solución propuesta: Se propone dejar la escombrera como tal, para la parte más septentrional del término municipal de Valdegovia. Para ello será necesario proceder a la retirada de los escombros existentes hacia los bordes para formar un caballón de talud natural. Asimismo se realizará la limpieza y retirada de basuras previa desinfección de los taludes exteriores de la escombrera y de la cuneta del camino. Esta última deberá limpiarse también de forma que el drenaje se produzca sin problemas. Finalmente para integrar los nuevos taludes en el paisaje se hará un aporte de T.V. seguido de hidrosiembra con mezcla de semillas tipo Hs.
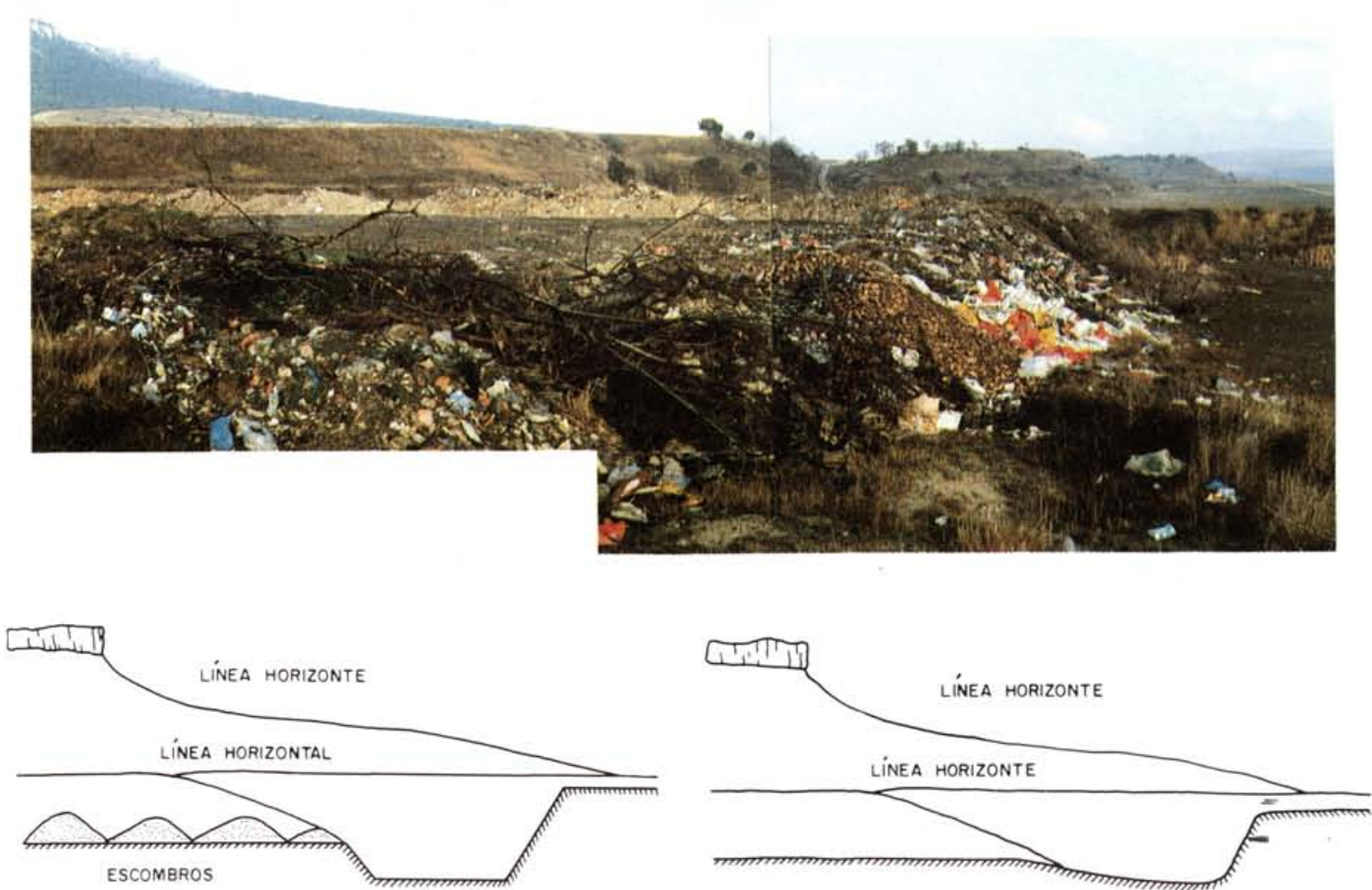


\section{N. de orden: 12 \\ Término Municipal: Lantarón \\ Núcleo:}

- Definición: Escombrera.

- Localización: Desviación a la derecha en el PK 31 (La playa) de la carretera local de Quintana Martín a Bergüenda que discurre paralela al río Ebro en sentido Miranda-Sobrón.

- Altitud: $600 \mathrm{~m}$.

- Suelo: Rendzina ochrica.

- Geologia: Terciario Neógeno, Mioceno inferior y medio. Sustrato de areniscas en paleocanales y arcillas.

- Vegetación: La vegetación es densa y variada, con un buen desarrollo y estado fitosanitario. Las especies más destacadas son: Q. ilex, Juniperus communis, Arbutus unedo, Buxus sempervirens, Q. coccifera, Erica vagans, Phyllirea angustifolia, Rubus sp., Rosa sp., Lonicera sp. El tapiz herbáceo cubre profusamente el suelo con especies como Koeleria vallesiana, Cynodon dactylon, Bromus sp., Festuca sp. Dactylis glomerata.

- Caracteristicas y problemática de los vertidos: La escombrera destaca en el paisaje por su desnudez y el color de sus materiales blanquecinos, dentro de un entorno cubierto de vegetación abundante y densa. Es visible desde la carretera de Miranda hacia Sobrón.

La escombrera presenta dos pisos con una pequeña plataforma intermedia de pequeñas dimensiones. En la cabecera del talud inferior se han desarrollado algunos ejemplares de Ailanto que ocultan en parte el talud superior.

- Solución propuesta: Para recuperar la zona se propone hacer, en primer lugar, un reperfilado de los taludes con extendido de los materiales sobrantes en la plataforma intermedia. Posteriormente, se procederá a la extensión de $20 \mathrm{~cm}$ de T.V. A continuación se plantarán al menos 3 de las 4 especies siguientes: madroños (A. unedo), Elaeagnus angustifolia, Acer monspessulanum y $Q$. ilex.

Finalmente se hidrosembrará toda la superficie con semillas tipo $\mathrm{H}_{\mathrm{S}}$.
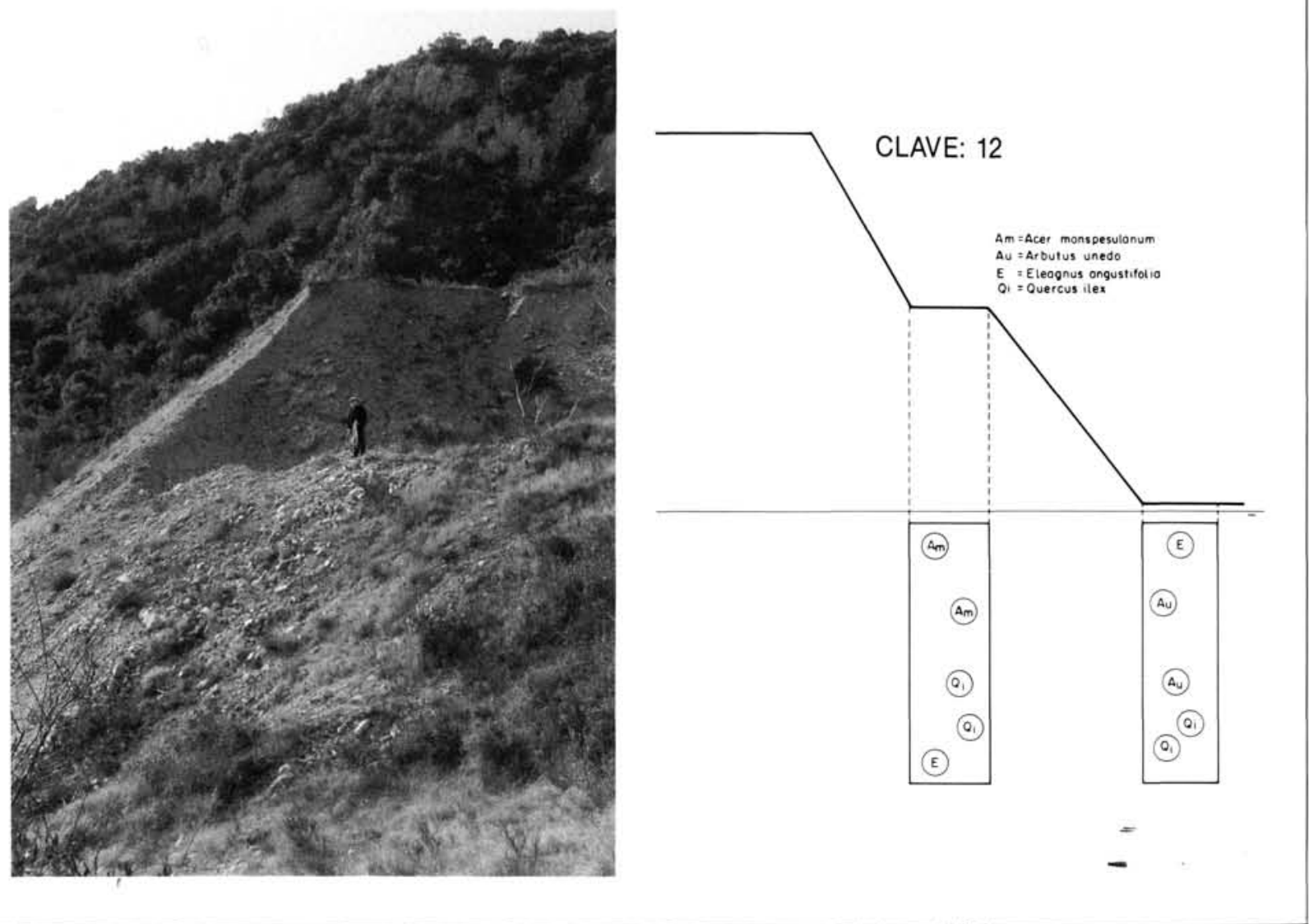


\section{N. de orden: 14}

Término Municipal: Lantarón

Núcleo:

- Definición: Escombrera.

- Localización: a pocos metros del arcén derecho de la carretera C-122 en sentido Fontecha - Miranda de Ebro a la altura del desvio a Caicedo-Yosu.

- Altura: $400 \mathrm{~m}$.

- Suelo: Cambisol cálcico.

- Geología: Cuaternario (Holoceno), aluvial limo-arenoso.

- Vegetación: Dominan las especies ruderales (Rubus sp. Echium sp., Dipsacus sp. Marrubium vulgare), debido al tipo de asentamiento (edificio en ruinas). Esta escombrera está situada entre cultivos (remolacha, cereal), cerca del río, donde dominan las alisedas (Alnus glutinosa).

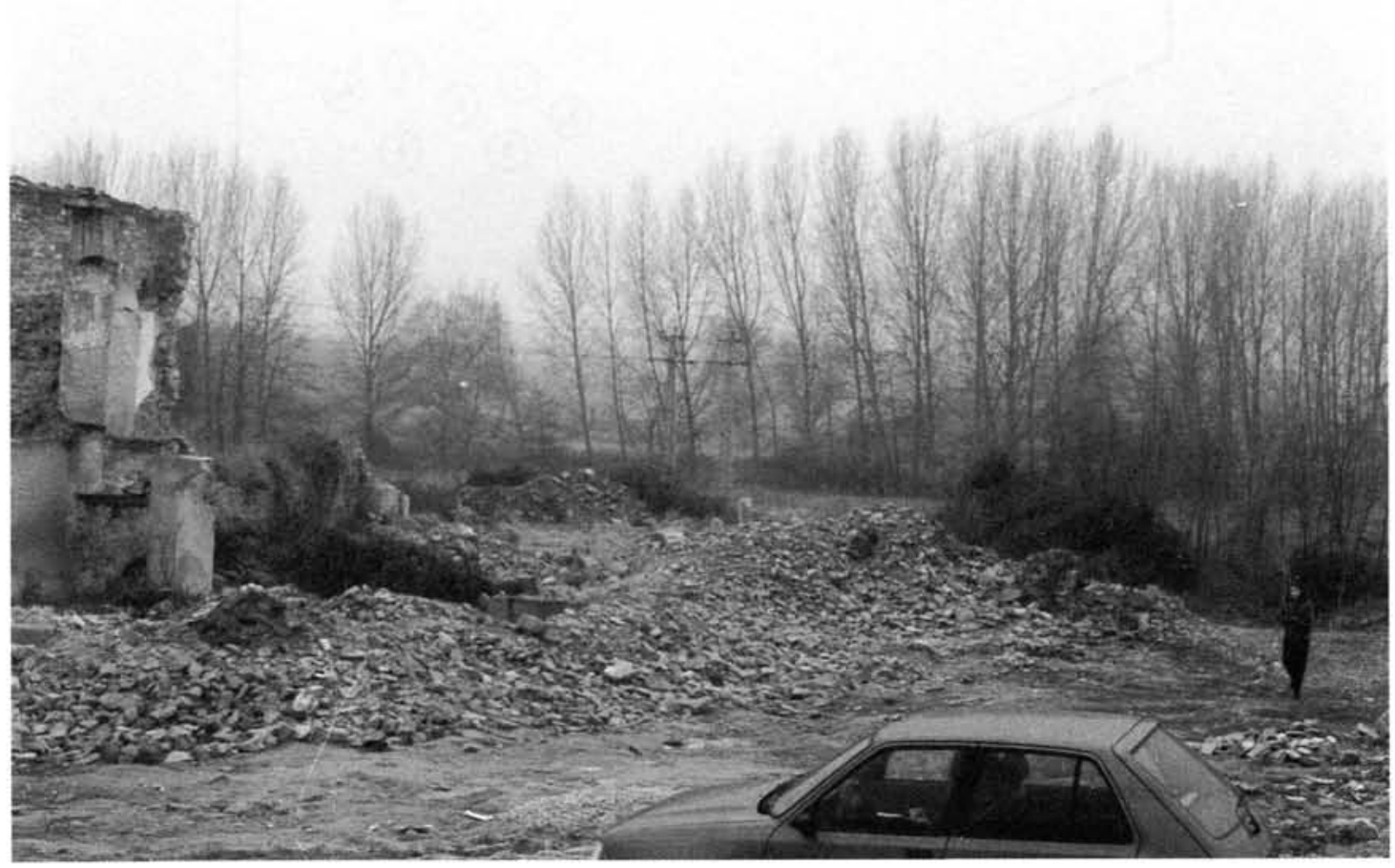

- Caracteristicas y problemática de los vertidos: La mayoria de los escombros proceden de las ruinas de una antigua casa de la que todavia se mantienen en pie algunos muros. Dada la naturaleza de los vertidos no presenta problemas de contaminación a pesar de encontrarse sobre las terrazas del Ebro, pero sí incide negativamente en el paisaje, sobre la vista desde la carretera, de la terraza baja del rio.

- Solución propuesta: Demolición, mediante maquinaria, de los muros de mamposteria existentes y posterior remodelación hasta dejar el terreno apto para la siembra. A continuación se aportará una capa de T.V. y se realizará una plantación con ejemplares de Juglans regia, Acer campestre, Salix atrocinerea y Crataegus monogyna según croquis adjunto. Para finalizar se hidrosembrará con hidrosiembra tipo $\mathrm{H}_{\mathrm{S}}$ para lograr su total integración en el medio. 

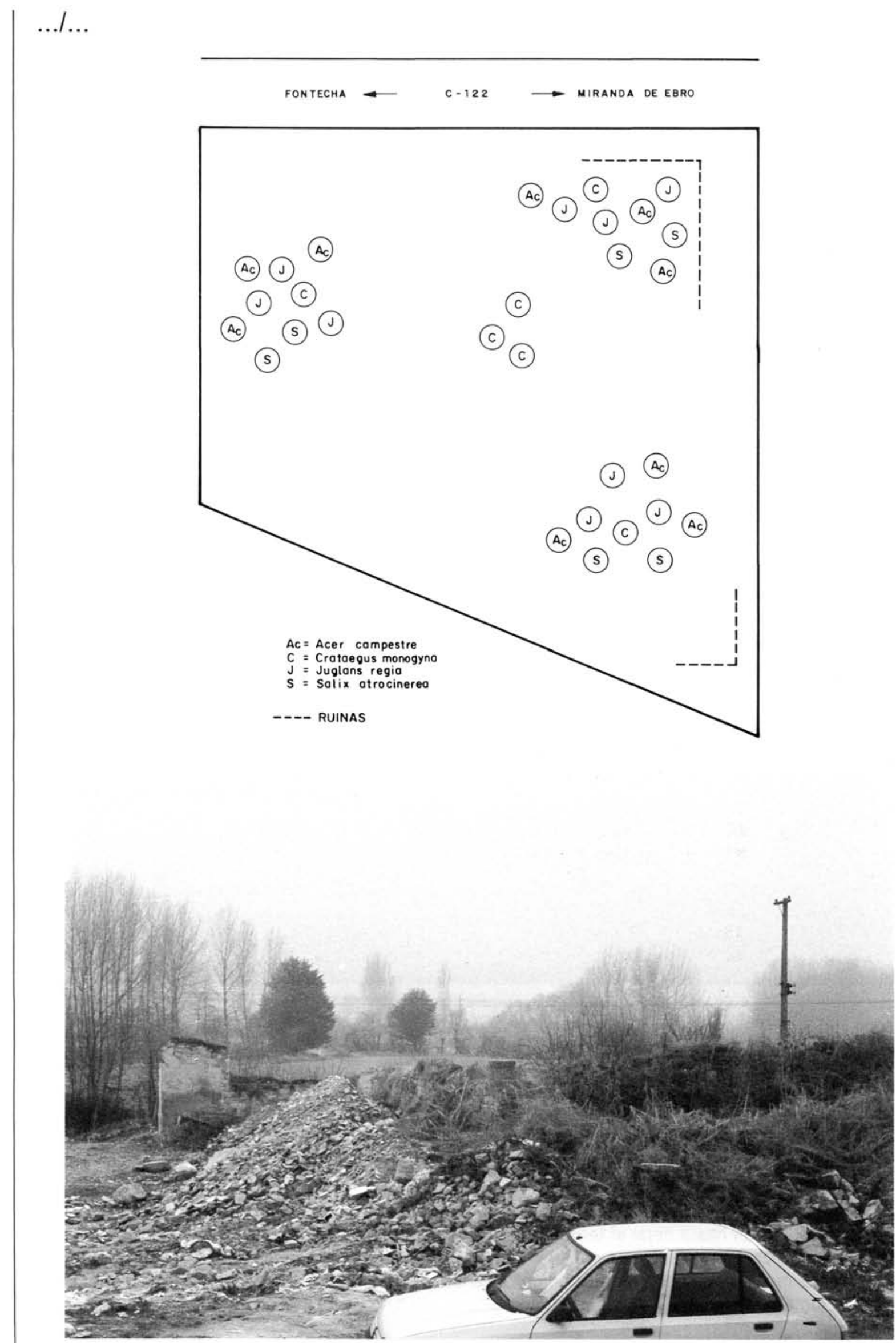


\section{N. de orden: 16 \\ Término Municipal: Ribera Baja Núcleo: Ribabellosa}

- Definición: Vertedero de residuos sólidos urbanos.

- Localización: Próximo a la carretera entre Comunión y Ribabellosa.

- Altitud: $500 \mathrm{~m}$.

- Suelo: Cambisol cálcico con inclusiones de cambisol vertico y regosol calcárico.

- Geología: Cuaternario (Pleistoceno), terraza media-baja.

- Vegetación: Localizado en una zona de pastizal duro, xerófilo de Festuca indigesta y Koeleria vallesiana con matas arbustivas, aisladas, de Thymus vulgaris, Genista scorpius y como consecuencia del vertido Rubus sp. Marrubium vulgare, Echium vulgare. Sobre los taludes erosionados aparecen matas de Euphorbia minuta, Globularia vulgaris, Linum apresum, Genista scorpius y Lavándula latifolia.

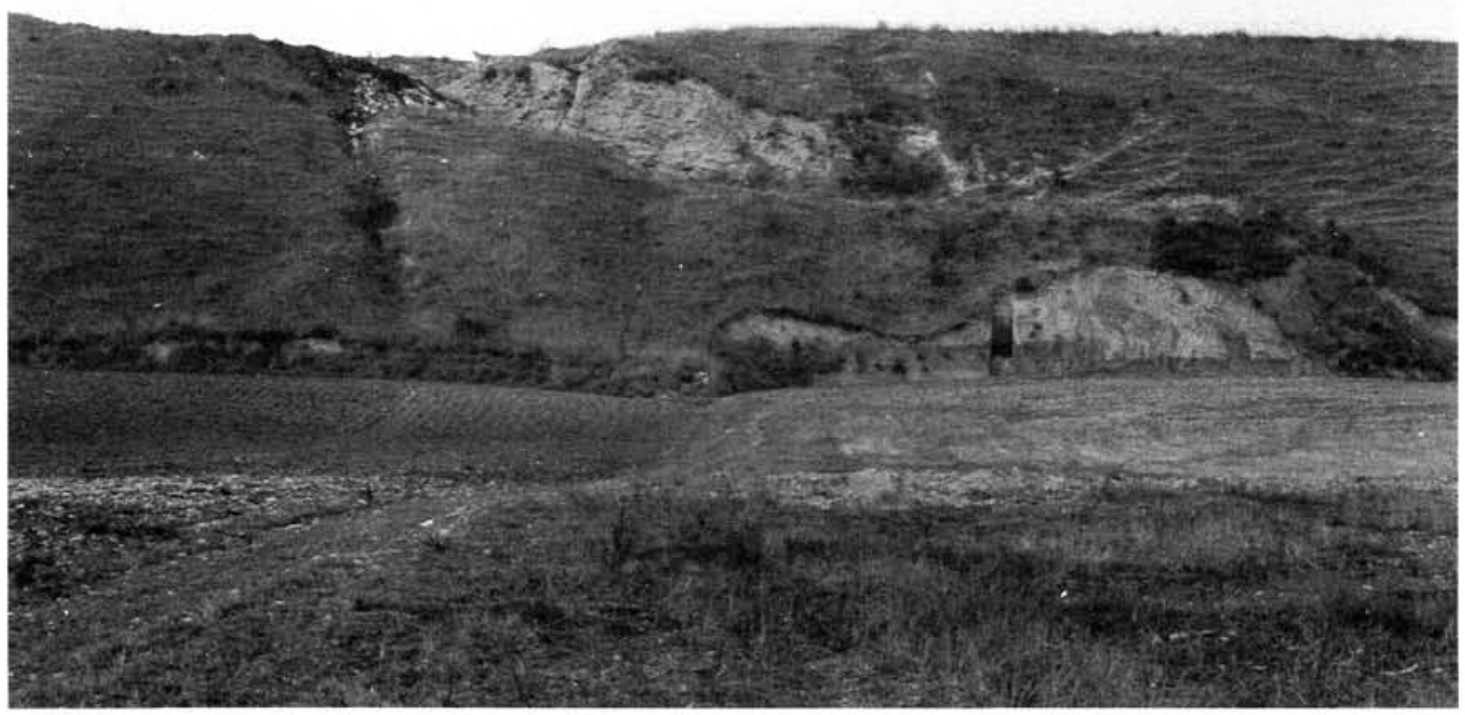

- Características y problemática de los vertidos: Vertedero asentado sobre un corte del terreno que recoge las basuras urbanas de Ribabellosa.

Produce un impacto negativo en el paisaje por la diferencia de color con los pastos xerófilos que lo rodean y ser un punto visible (cota elevada en el conjunto del entorno).

- Solución propuesta: Dada la naturaleza de los vertidos y su ubicación, en el limite con terrenos del Cuaternario se procederá al sellado y recuperación del mismo.

En primer lugar se procederá a desinfección, seguido de un remodelado del terreno, aporte de una capa de suelo cohesivo (arcilla) de $20 \mathrm{~cm}$ de espesor, para impedir la salida de gases (tipo metano) originadas por la fermentación de basuras y la contaminación producida por lavado de aguas de llưia. Posteriormente se aportará una capa de T.V., y se realizará una hidrosiembra tipo $\mathrm{H}_{\mathrm{S}}$. 


\section{LIMPIEZA DE PEQUEÑOS VERTIDOS INCONTROLADOS}

En este capítulo se incluyen aquellos puntos de vertido que, dado su escaso volumen de residuos, se co. rregirán fundamentalmente mediante labores de limpieza. Corresponden a poblaciones de muy bajo número de habitantes que realizan sus vertidos de forma difusa e incontrolada. Para estas labores de limpieza se destinará una partida alzada en el presupuesto.

La limpieza y recogida de basuras en núcleos urbanos, de menos de 50 habitantes, constará de:

- Recogida de basuras y limpieza de la zona.

- Carga en remolque agrícola.

- Transporte hasta el lugar de recogida general fijado por la Diputación Foral de Álava para cada nú. cleo urbano.

- Carga en el camión de recogida que lleva la basura hasta el vertedero controlado de Gardélegui. El coste de este transporte no se incluye en el coste de ejecución material de la actividad indicada.

\section{ESCROMBERAS PROPUESTAS PARA SU FUTURA UTILIZACIÓN}

La solución propuesta para los vertidos incontrolados de escombros, ha sido la localización de cuatro emplazamientos como escombreras.

En primer lugar se han considerado las ya existentes y los problemas que su uso aportaba. Cuando éstos han sido mínimos y su emplazamiento ha resultado adecuado, tenidas en cuenta todas las variables del medio afectadas, se han propuesto para su futura utilización.

En el caso de no poder considerar ningún emplazamiento oportuno para su empleo como futura escombrera se realizará un estudio detallado que abarque la totalidad del territorio de ese término municipal. Este estudio aportará las situaciones óptimas que serán las que en este proyecto se propongan.

\section{ESCOMBRERAS EXISTENTES}

Las escombreras propuestas para su futura utilización y ya existentes han sido:

- Villanueva Vaidegovía.

- Osma.

- Espejo.

- Ribabellosa.

(c) Consejo Superior de Investigaciones Científicas Licencia Creative Commons 3.0 España (by-nc)

\section{LOCALIZACIÓN DE UNA ESCOMBRERA EN EL T.M. DE LANTARÓN}

En el presente apartado, se ha realizado el estudio de localización de una nueva escombrera (para el depósito de residuos sólidos), en el Término Municipal de Lantarón.

Dicho estudio, ha tomado como base la información contenida en los mapas 1:50.000 (cartografia militar de España; cartografía e inventario vegetal de la provincia de Álava) para lograr una primera aproximación, que se ha concretado de modo definitivo tras el trabajo de campo y el estudio de la cartografía a escala 1:5.000.

Como factores del medio determinantes para la localización de la escombrera, y supuesto que no existen restricciones de carácter hidro-geológico, por tratarse exclusivamente de vertido de escombros, se han selec. cionado los siguientes:

\section{A-Geomorfología. \\ B-Vegetación y usos actuales del suelo. \\ C-Accesibilidad.}

\section{A. Geomorfología}

Mediante la consideración de este elemento se puede disponer, tras la delimitación de las correspondientes unidades geomorfológicas o de paisaje, de una cartografía sintética que informe acerca de las formas generales del terreno y las principales características visuales del territorio.

Dicha delimitación se ha llevado a cabo sobre el mapa topográfico a escala 1:50.000, obteniéndose los resultados que aparecen en el mapa de Unidades de Paisaje (Mapa 1).

La clave correspondiente a este mapa es la siguiente:

1) Unidades que vierten sus aguas directamente al rio Ebro.

2) Valles perpendiculares al río Ebro, de orientación preferente NE-SW.

3) Pequeños valles perpendiculares a los definidos en 2), con orientación preferentemente NW-SE, que pueden considerarse como subunidades de las anteriores.

4) Pequeños valles perpendiculares a los definidos en 2), con orientación preferente NW-SE.

5) Valles altos, o cabeceras de ríos, de orientación general N-NE.

http://informesdelaconstruccion.revistas.csic.es 


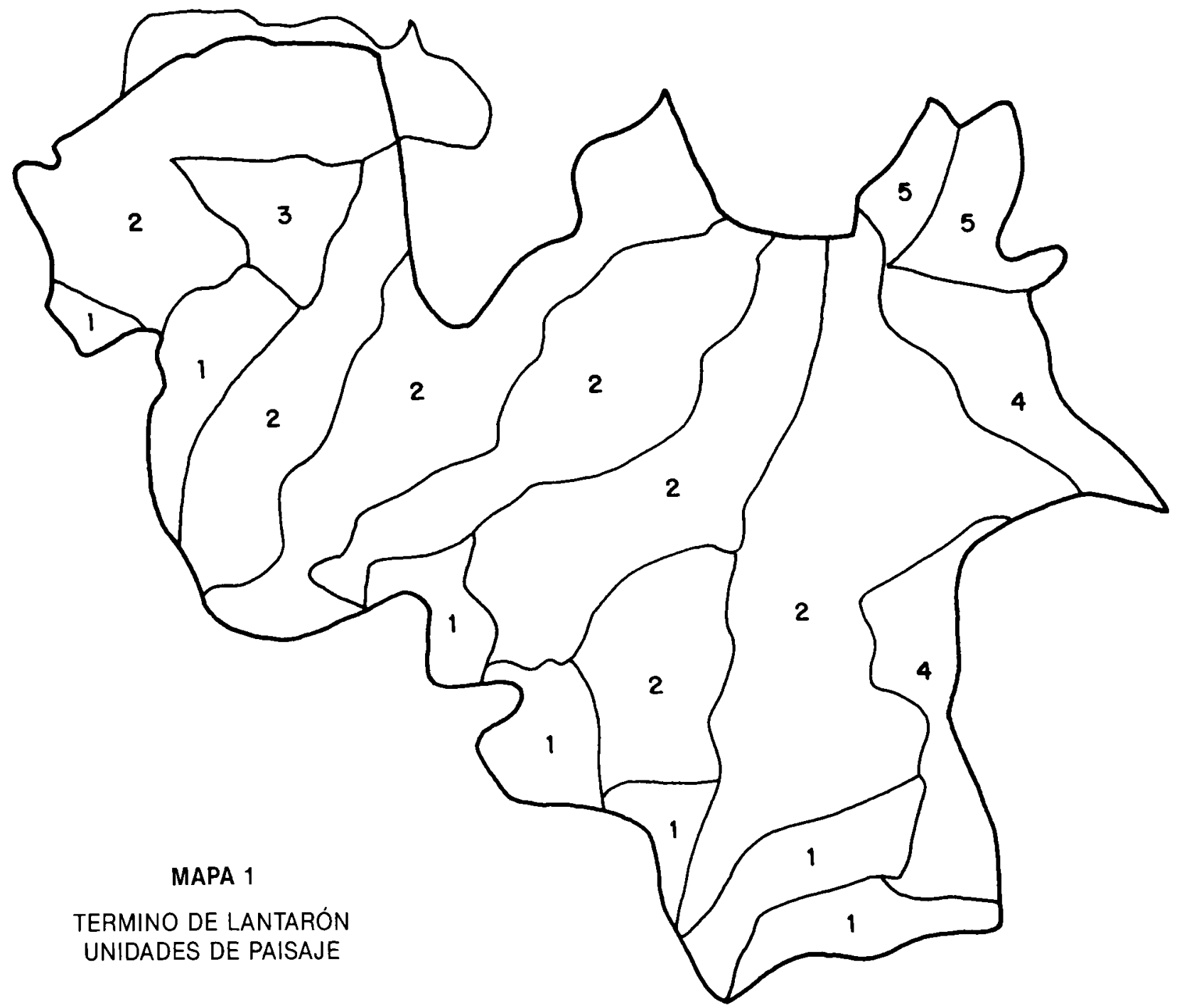

\section{B. Vegetación.}

La consideración de este elemento se ha realizado a través de una doble vertiente:

- el valor ecológico y

- los aspectos visuales

de las distintas formaciones vegetales presentes en el área.

En cualquiera de sus dos aspectos, en este caso, la vegetación ha constituido un elemento restrictivo para la localización de la escombrera. De este modo tan só. lo se han reseñado aquellas formaciones que hacen im. posible la localización de la escombrera en su interior.
C. Accesibilidad.

Como en el caso de la vegetación, se han tenido en cuenta únicamente las restricciones a la localización derivada de una accesibilidad deficiente. Se ha considerado necesario, para la óptima ubicación de la futu. ra escombrera, que ésta se pueda comunicar, con los distintos núcleos del término, a través de caminos o carreteras practicables con camiones.

\section{INTEGRACIÓN}

Mediante la superposición de los mapas de Unidades de Paisaje, Vegetación y Accesibilidad, s ha logrado una caracterización de las distintas unidades definidas en el apartado A, Cuadro II. 
Cuadro II

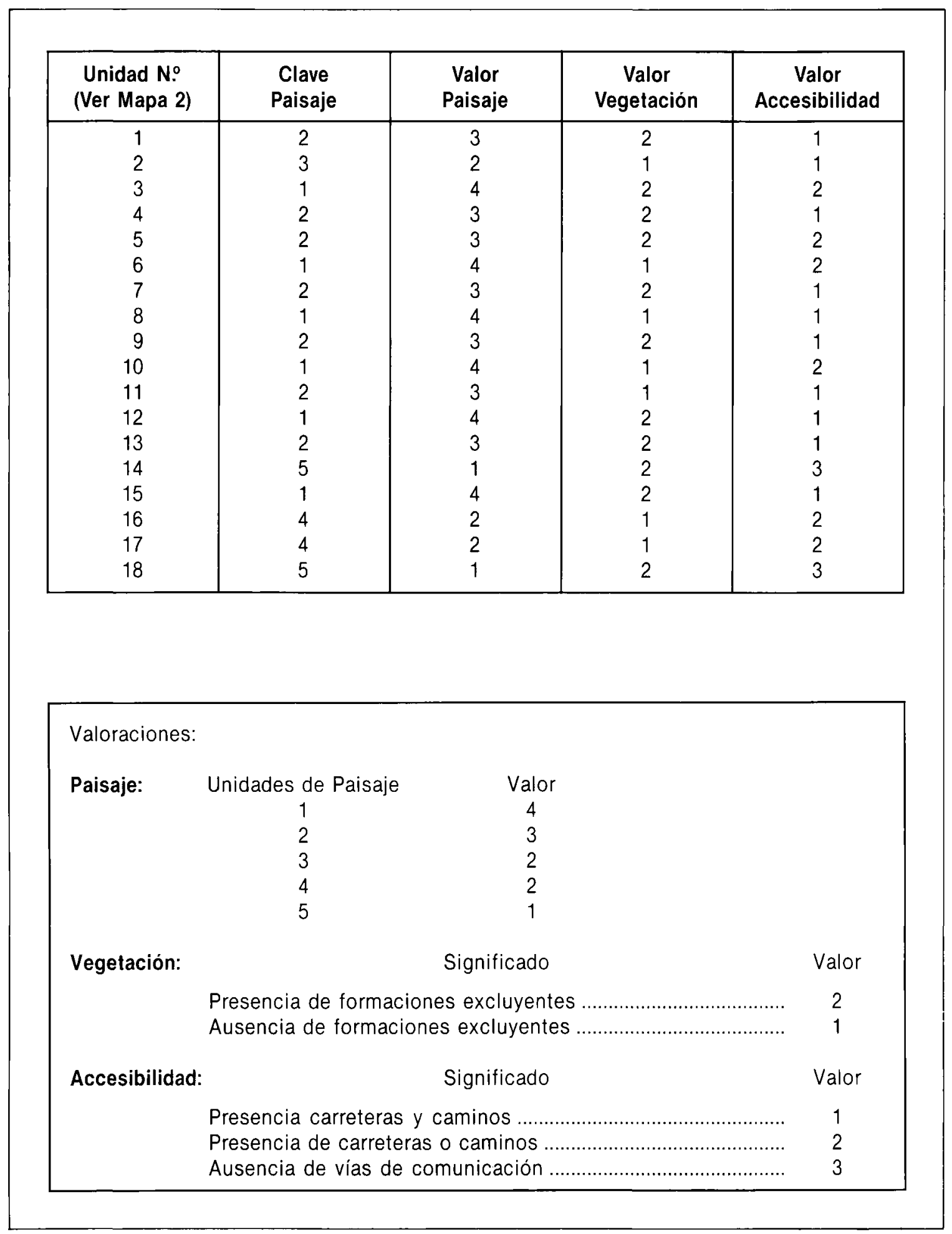




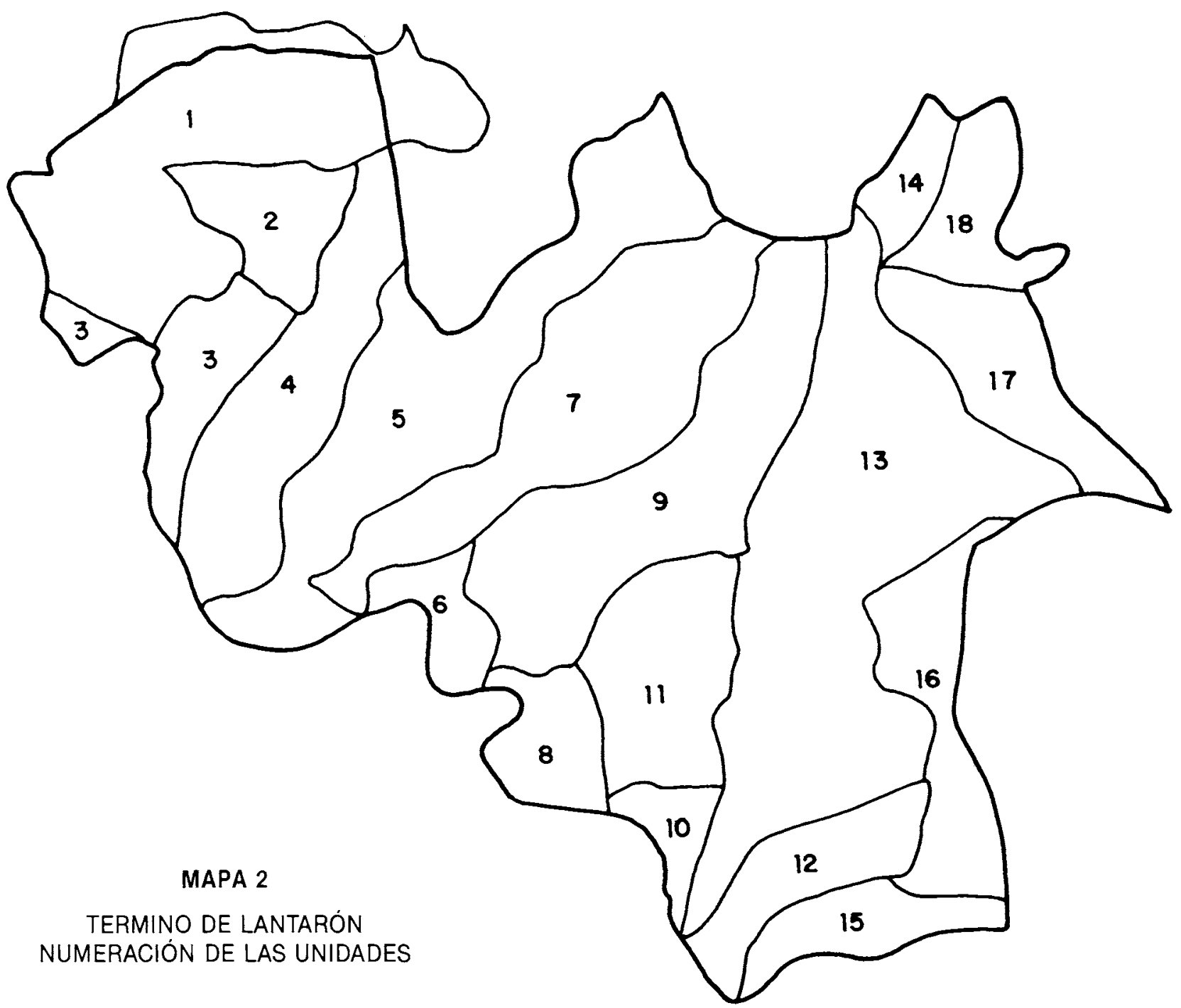

En todos los casos se ha hecho corresponder el valor 1 con el mejor, con el fin de poder aplicar el método de las precedencias (OTERO, 1979).

Cada una de estas unidades ha quedado pues caracterizada por un vector de tres coordenadas (geomorfologia, vegetación y paisaje); la aplicación del método de las precedencias a ese conjunto de vectores ha proporcionado la ordenación del cuadro III, del cual se deduce que la localización óptima de la escombrera corresponde a la Unidad n. 2.

La decisión sobre el nuevo emplazamiento dentro del territorio delimitado por esta unidad, quedará supeditada a la necesidad real de su utilidad en razón a las distancias a las escombreras que ya existen y han sido propuestas en este proyecto.

\section{RECOMENDACIONES GENERALES PARA LA GESTIÓN DE LAS ESCOMBRERAS}

- Mantener en buen estado el camino de acceso a las mismas.

- Depósito de escombro de forma que no sobresalga en el paisaje.

- Rellenar por zonas de forma que los escombros no queden diseminados sin ningún orden, empezando siempre por el punto más alejado de la entrada.

- Evitar caidas del material a descargar, fuera de los límites de la escombrera.

- Determinar legalmente la obligatoriedad de su uso como tal y no cualquier otra zona.

- Revisión periódica (a determinar) para comprobar el estado de su uso y gestión, asi como el de sus alrededores. 


\section{Cuadro III}

\begin{tabular}{|c|c|c|}
\hline Unidad N. & Precede a & Es precedida por \\
\hline 1 & 6 & 6 \\
2 & 18 & 2 \\
3 & 2 & 16 \\
4 & 6 & 6 \\
5 & 4 & 12 \\
6 & 4 & 8 \\
7 & 6 & 6 \\
8 & 6 & 4 \\
9 & 6 & 6 \\
10 & 4 & 8 \\
11 & 12 & 3 \\
12 & 3 & 8 \\
13 & 6 & 6 \\
14 & 4 & 6 \\
15 & 3 & 8 \\
16 & 12 & 4 \\
17 & 12 & 4 \\
18 & 4 & 6 \\
\hline
\end{tabular}

\section{BIBLIOGRAFIA}

- CLARK R.M. y GUILLEAN, J.I., 1981. Resource Recovery Planning and Management. Ann Arbor Science. Michigan.

- CONSEJO DE EUROPA, 1988. Naturopa (N. monográfico dedicado a residuos). Naturopa 58 , Consej. de Europa.

- DIRECCIÓN GENERAL DEL MEDIO AMBIENTE, 1980. La recuperación de recursos de los residuos. MOPU, DGMA.

- ENVIRONMENTAL IMPACT ASSESSMENT RESEARCH, 1988. Número especial dedicado a residuos. Vol. 8 n. 2. Elsevier.
- HERRAEZ, J. et al 1989. Residuos Urbanos y Medio Ambiente. Edcs. de la Universidad Autónoma de Madrid.

- MONJOJE, A. 1987. Méthodologie de préservation des sites d'épandage des déchets ménagers. Le Tribune Cebedeau Vol. 40, 529: 35-38.

- OTERO, I. 1979. El análisis cuantitativo de ios elementos del medio natural en orden a la Planificación Física. Tesis Doctoral. E.T.S. I. de Montes, UPM.

- OTERO PERAL, L. 1988. Residuos Sólidos Urbanos. MOPU, DGMA.

- SOPPER, W.E., 1989. Revegetation of a contamina. ted zinc smalter site. Landscape and Urban Planning $17: 241-50$. 